\title{
Experimental study of modified raw soil block bending strength Zhiqiang LI ${ }^{\mathrm{a}}$, Guoqing WANG ${ }^{\mathrm{b}^{*}}$, Sen YANG ${ }^{*}$
} College of Water Conservancy \& Architectural Engineering, Shihezi University, Shihezi 832000,
China

azhiqiangli2023@163.com; b1543776250@qq.com; c734885028@qq.com

${ }^{*}$ Corresponding Author: Guoqing WANG, Sen YANG. College of Water Conservancy \& Architectural Engineering, Shihezi University.

Keywords: modified raw soil, bending strength, orthogonal experiment, optimum mixture ratio Abstract: Single factor test was applied to study on the engineering properties of modified raw soil, by which the reasonable range of grass, cement, quick lime, and fly ash were determined. The effects of various factors on the bending strength of modified raw soil were studied by orthogonal test method, and the experimental results were analyzed. The experimental results show that the order of influence on the bending strength of modified raw soil block was glass $\mathrm{A}>$ cement $\mathrm{C}>$ quick lime D> fly ash B. Finally, the optimal mixture ration of modified raw soil was determined.

\section{Introduction}

As the most widely used structural form in rural areas of China, the raw soil structure houses have the advantages of local conditions, local materials and simple construction and so on[1-3]. In this paper, the raw soil of Shihezi regiment is selected, and the engineering properties of the modified raw soil are studied by mixing the glass, fly ash, cement and quick lime. This study provides the theory for improving the comprehensive performance of the raw soil block, such as compressive strength, bending resistance and durability.

\section{Single Factor Experiment}

Test material: Clay: supplied by Shihezi 150 Regiment. Cement: $32.5 \mathrm{R}$ composite Portland cement. Grass: corn stalks, length $\leq 50 \mathrm{~mm}$. Fly ash: Class I fly ash. Water: tap water.

Single factor test and analysis: The size of specimen of is $100 \mathrm{~mm} \times 100 \mathrm{~mm} \times 100 \mathrm{~mm}$, and the $28 \mathrm{~d}$ compressive strength test results were shown in Fig. 2(1)-(4).

As shown in fig.1(1), when the content of grass is [0\%, 0.25\%], the compressive strength increase gradually; when the content of grass is $[0.25 \%, 0.5 \%]$, the compressive strength gradually decreased; and when the content of grass is [0.5\%, $1.0 \%]$, the compressive strength gradually stabilized. Therefore, the reasonable range of the content of the grass is $[0 \%, 0.25 \%]$.

As shown in fig.1 (2), when the content of fly ash is $[0 \%, 5 \%]$ and $[10 \%, 15 \%]$, the compressive strength increase gradually; when the content of fly ash is [5\%,10\%] and [15\%, 20\%], the compressive strength gradually decreased; and the compressive strength with the content of 5\% is higher than $10 \%$. Therefore, the reasonable range of the content of fly ash is $[0 \%, 5 \%]$.
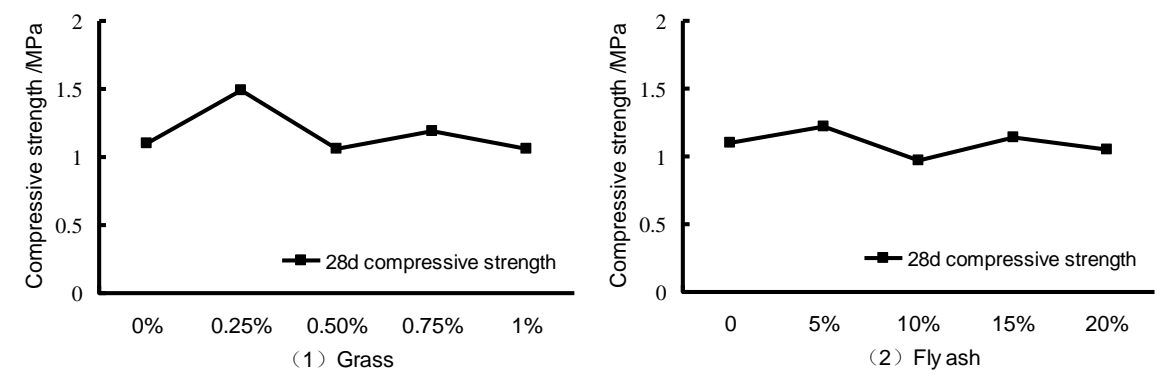

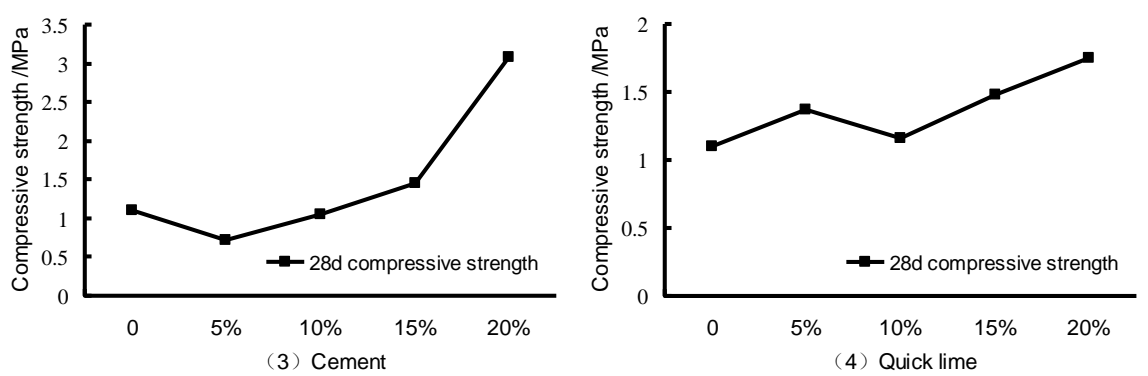

Fig.1 Relationship between the factors and 28d compressive strength of raw-soil blocks

As shown in fig.1 (3), when the content of cement is [0\%, 5\%], the compressive strength decreases; when the content of cement is $[5 \%, 20 \%]$, the compressive strength increase gradually; and when the content of cement is [15\%,20\%], the compressive strength increases significantly. Therefore, the reasonable range of the content of cement is [15\%, 20\%].

As shown in fig.1 (4), when the content of quick lime is $[0 \%, 5 \%]$ and $[10 \%, 20 \%]$, the compressive strength increase gradually; when the content of quick lime is [5\%, 10\%], the compressive strength decreased gradually; and when the content of quick lime is $5 \%$ and $15 \%$, the strength of the relatively close. Therefore, the reasonable range of content of quick lime is $[0 \%$, $5 \%]$.

\section{The Orthogonal Experiment}

Orthogonal experimental design. Based on the optimal values of the factors obtained from the single factor experiment, the interval of each parameter was refined. In order to reduce the test workload, orthogonal design method was used. The factor's level of test is shown in table.1.

\begin{tabular}{ccccc}
\hline Factor & Grass A (\%) & Fly ash B (\%) & Cement C (\%) & Quick lime D (\%) \\
\hline test1 & $0(\mathrm{~A} 1)$ & $0(\mathrm{~B} 1)$ & $15(\mathrm{C} 1)$ & $0(\mathrm{D} 1)$ \\
test2 & 0 & $2.5(\mathrm{~B} 2)$ & $17.5(\mathrm{C} 2)$ & $2.5(\mathrm{D} 2)$ \\
test3 & 0 & $5(\mathrm{~B} 3)$ & $20(\mathrm{C} 3)$ & $5(\mathrm{D} 3)$ \\
test4 & $0.15(\mathrm{~A} 2)$ & 0 & 17.5 & 5 \\
test5 & 0.15 & 2.5 & 20 & 0 \\
test6 & 0.15 & 5 & 15 & 2.5 \\
test7 & $0.25(\mathrm{~A} 3)$ & 0 & 20 & 2.5 \\
test8 & 0.25 & 2.5 & 15 & 5 \\
test9 & 0.25 & 5 & 17.5 & 0 \\
\hline
\end{tabular}

Experimental result. According to test method of GB/T 4111-2013, the raw soil block bending strength results were shown in table 2 .

Table.2 The results of compressive strength

\begin{tabular}{cccccccccc}
\hline Test & Test 1 & Test 2 & Test 3 & Test 4 & Test 5 & Test 6 & Test 7 & Test 8 & Test 9 \\
\hline $\begin{array}{c}\text { 28d Bending } \\
\text { strength /MPa }\end{array}$ & 0.63 & 0.68 & 0.73 & 1.16 & 1.29 & 0.91 & 1.07 & 1.09 & 1.12 \\
\hline
\end{tabular}

According to results of table 1 and table 2, the range analysis of orthogonal test can be obtained as shown in table.3.

Table. 3 The range analysis of orthogonal test

\begin{tabular}{cccccc}
\hline \multirow{2}{*}{ Test } & Range analysis & \multicolumn{5}{c}{ Factor of influence } \\
\cline { 3 - 6 } & & $\mathrm{A}$ & $\mathrm{B}$ & $\mathrm{C}$ & $\mathrm{D}$ \\
\hline & $I_{\mathrm{j}}$ & 2.040 & 2.859 & 2.661 & 2.979 \\
& $I_{\mathrm{j}}$ & 3.330 & 3.06 & 2.931 & 2.661 \\
28d Bending & $I I I_{\mathrm{j}}$ & 3.279 & 2.73 & 3.06 & 3.009 \\
strength & $K_{1}$ & 0.680 & 0.953 & 0.887 & 0.993 \\
/MPa & $K_{2}$ & 1.110 & 1.020 & 0.977 & 0.887 \\
& $K_{3}$ & 1.093 & 0.910 & 1.020 & 1.003 \\
& $R$ & 0.430 & 0.110 & 0.133 & 0.116 \\
\hline
\end{tabular}


It can be seen that the order of influence on the bending strength of modified raw soil block was glass $\mathrm{A}>$ cement $\mathrm{C}>$ quick lime $\mathrm{D}>$ fly ash $\mathrm{B}$.

Factors analysis of Bending Strength. According to orthogonal test, the bending strength of each factor at different levels can be obtained by factors analysis, as shown in fig.2 (1)-(4).
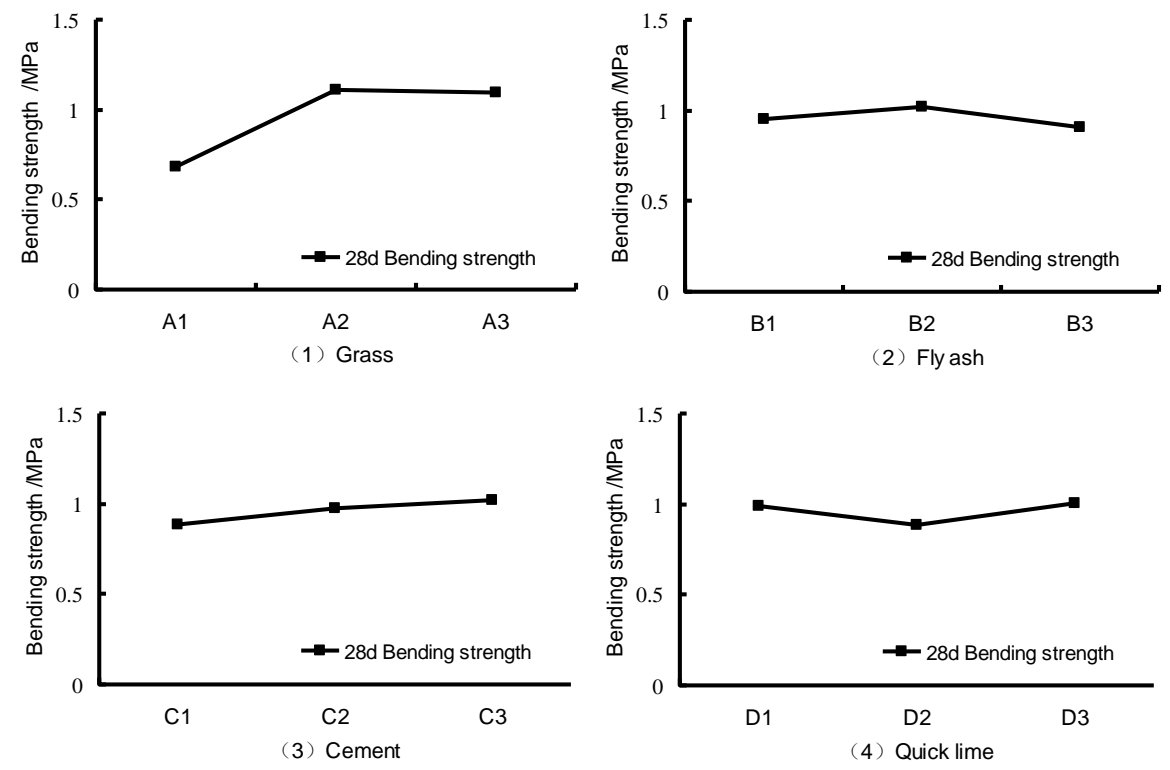

Fig.3 Relationship between 4 factors and bending strength

In fig.2(1), it can be seen that when the content of grass is [0\%, $0.25 \%$ ], the bending strength increases gradually, but when the content of grass is [0.15\%, $0.25 \%]$, the bending strength stabilizes. Therefore, the optimal ratio of the content of grass is $0.15 \%$.

In fig.2(2), it can be seen that when the content of fly ash is $[0 \%, 2.5 \%]$, the bending strength increases gradually, but when the content of fly ash is $[2.5 \%, 5 \%]$, the bending strength decreases. Therefore, the optimal ratio of the content of fly ash is $2.5 \%$.

In fig.2(3), it can be seen that when the content of cement is $[15 \%, 20 \%]$, the bending strength increases gradually. Therefore, the optimal ratio of the content of cement is $20 \%$.

In fig.2(4), it can be seen that when the content of quick lime is $[0 \%, 2.5 \%]$, the bending strength reduces gradually, when the content of quick lime is $[2.5 \%, 5 \%]$, the bending strength increases gradually. Considering the durability of raw soil, therefore, the optimal ratio of the content of quick lime is $5 \%$.

The optimal mixture ration of modified mud was determined as A2B2C3D3 by factors analysis. The content of the grass dosage is $0.15 \%$, the content of fly ash was $2.5 \%$, the content of cement was $20 \%$ and the content of quick lime was $5 \%$.

\section{Variance analysis.}

Table 4 The variance analysis of orthogonal test

\begin{tabular}{ccccccc}
\hline Indicators & Element & Bias squares & Degrees of freedom & F ratio & F critical value & Significant \\
\hline \multirow{3}{*}{ 28 d Bending strength } & A & 0.365 & 2 & 3.274 & $\mathrm{~F}_{0.01}=8.65$ & $*$ \\
& $\mathrm{~B}$ & 0.016 & 2 & 0.143 & $\mathrm{~F}_{0.05}=4.46$ & -- \\
& $\mathrm{C}$ & 0.037 & 2 & 0.332 & $\mathrm{~F}_{0.10}=3.11$ & -- \\
\hline
\end{tabular}

The results of variance analysis of orthogonal test were shown in Table 4. It can be seen that the factor of Grass A has significant influence on bending strength of the modified raw soil block, followed by factors of C, D and B.

\section{Conclusions}

The most important conclusions that can be drawn from this study were as follows:

(1)The reasonable range of grass is $[0 \%, 0.25 \%]$, the reasonable range of fly ash is $[0 \%, 5 \%]$, the 
reasonable range of cement is $[15 \%, 15 \%]$, and the reasonable range of quick lime is $[0 \%, 5 \%]$. (2)The order of the influence on the bending strength of the modified raw soil block was glass A> cement $\mathrm{C}>$ quick lime $\mathrm{D}>$ fly ash $\mathrm{B}$.

(3)The optimal mixture ratio is $\mathrm{A} 2 \mathrm{~B} 2 \mathrm{C} 3 \mathrm{D} 3$. The content of grass is $0.15 \%$, the content of fly ash is $2.5 \%$, the content of cement is $20 \%$ and the content of quick lime is $5 \%$.

\section{Acknowledgments}

This project is sponsored by National Natural Science Foundation of China (Grant No. 51668053, 2015BAL03B02), and the High-Level Personnel Scientific Research Projects (RCZX201324).

\section{References}

[1] Yihong Wang, Pengbo Ma, Kun Zhang etc. Journal of Xian university of science and technology, 2015, 30 (6): 768-773.

[2] Yihong Wang, Jian Liang, Xiangying Zhang etc. Journal of civil engineering, 2015, 48 (5): 98-107.

[3] Yun Wang. Building science, 2011, 27 (11): 49-50. 